\title{
MODELING A MANUFACTURING ENTERPRISE-A SYSTEMS APPROACH
}

\author{
PSRK Nageswara Rao ${ }^{1 *}$, P. Usha $\mathrm{Sri}^{2}$, K. Vizayakumar ${ }^{3}$ \\ ${ }^{1}$ Department of Mechanical Engineering, SVIET, Nandamuru, India, \\ ${ }^{2}$ Department of Mechanical Engineering, UCE, OU, Hyderabad, India. \\ ${ }^{3}$ Department of Mechanical Engineering, BEC, Bapatla, India \\ ${ }^{1}$ Email: panugantisrk@gmail.com* (Corresponding author) \\ ${ }^{2}$ Email:emailushasri@yahoo.com \\ ${ }^{3}$ Email: vizaya@gmail.com
}

\begin{abstract}
Understanding the context and problems of a manufacturing enterprise (ME) and its internal dynamics, primarily through modelling by its processes, operations, and activities. This paper attempts to provide a deeper understanding of the structure and internal mechanisms of ME that shape the overall dynamic behaviour through system dynamics modelling. In this paper, we discuss the system dynamics model in detail and present the insights gained from running simulations. This model helps to explore various policy options relating to decisions and it can be applied to predict system behaviour and gain insights using sound engineering and scientific principles and techniques before implementing a new policy. The paper describes major influences in ME from a system perspective, problems inherent in production systems made clear because the modelling of causal loops introduce cross-departmental issues and promote process Integration. This model guides managers through a continuous improvement process relative to addressing physical, policy or paradigm constraints in their production system.
\end{abstract}

Keywords: System Dynamics, Manufacturing Enterprise, Causal Loop Diagram, Policy

https://doi.org/10.47412/WRZC7993

\section{Introduction:}

The present manufacturing Enterprises (ME) are challenged by intense global competition characterized by changing customer requirements. During the last decades, MEs in pursuit of cost reduction without compromising the quality is becoming an objective of researchers as well as practicing managers. The main reason for the investigation of manufacturing systems is to understand, analyse and control the non-linear behaviour of its processes that will make more productive and predictive[1]. The intricate interrelationship among the system elements with stochastic nature, make the mathematical modelling quite challenging [2]. The challenge of demand variability, order amplifications and instability is complicated by delayed production [3]. When customer demand varies management has to adjust the capacity utilization to maintain adequate service levels to avoid excess inventory. To address these problems earlier researchers are adopted Total Quality Management(TQM) and Just In Time (JIT). Methods such as JIT, TQM, and value-adding management have enabled industries to reduce the inventories, improve quality, lower rejection rates and better production efficiency[4][5]. 
In the following sections of the paper, a simulation model (i-THINK)[6] is used to help to explain the internal mechanisms in the production and inventory system and by using the model in evaluating various policy options.

\section{System thinking:}

Whenever we make decisions and the corresponding action, there will be some consequences. These consequences may be within the control. The information produces actions that have consequences, generating, further information and actions. Developing an increasingly deep understanding of the structure by making reliable interferences about system behaviour is done by system thinking. It requires to first define a system; a system is a collection of elements of an organization which are organized for a purpose. System thinking makes one understand the subtest aspect of an organization is a new way of individual entrepreneurs to perceive themselves and their world. A place where people are constantly discovering how they build one's reality is known as a learning organization. The thinking position has both structural and behavioural implications that view generic as well specific. The first aspect if system thinking concentrates system as cause thinking, closed-loop thinking, and operational thinking. The thinking position has both structural and behavioural implications that view generic as well specific. The second aspect if system thinking concentrates system as cause thinking, closed-loop thinking, and operational thinking. The cause system thinking deals with how an element in the system influences another element either increase or decrease in the. The closed-loop thinking develops the feedback structure of how these are connected in a cycling nature which creates the dynamic hypothesis and endogenous viewpoint. The operational thinking is the consideration of the details on how to implement and manage the policies throughout the organization and integrate the management techniques into an organization wise system and put the planning into action by tracking, maintain, responding and adjusting whenever necessary.

\section{System Dynamics:}

Forrester and colleagues at MIT were the originators and continue as the major developers of the system dynamics approach. The approach was named Industrial Dynamics, originally [7]. The system dynamics are definitely highly refined and accurate in terms of their stability and responses to external shocks. In some cases, the presenting instability may be so gross that exact analyses are not required. System dynamics provides a way of simulating such systems and approximate modelling. System Dynamics is based on the philosophy that the behaviour of the system is principally causing by its structure based on policies and traditions, and the structure of an organization can be best represented in terms of underlying flows of various resources cutting across the functional departments tracing various feedback loops, delays, and applications of the system. System structure leads to system behaviour and to system events in fundamental to contemporary system dynamics events are short, immediately and time scale whereas, the behaviour represents the fluctuations over a long period[8]. A fundamental assumption of system dynamics is that the behaviour is a result of structure. The structure defines how the variables interact with the other variables and define what are the causes of this behaviour. The behaviour of business processes is a function of its characteristic system that recommends any redesign of such a process requires to concentrate on the rethinking of those structures.

A model feedback system emphasis to concentrate on its structure rather than the content. The presence of delays in moving goods and transmitting information, perhaps the root causes of observed events in some distance away in space-time. The analysis of symptoms may not lead to real causes unless there is a deep understanding of the operations of the system structure. The structure of the business process causes the behaviour of the system. 


\section{Case Study}

ABC Ltd is a small and medium-sized disposable needles manufacturing company in India. ABC Ltd produces a wide range of gauges of needles according to the market requirements. To study in-depth about understanding the activities, processes involved in this organization and then mapping the material flow, informational flow, and control flow to develop the system structure. The process is defined in terms of enterprise activities, these activities are processing steps within the process transforming the objects and is used to support further system analysis and device new policies for the improvement of the system.

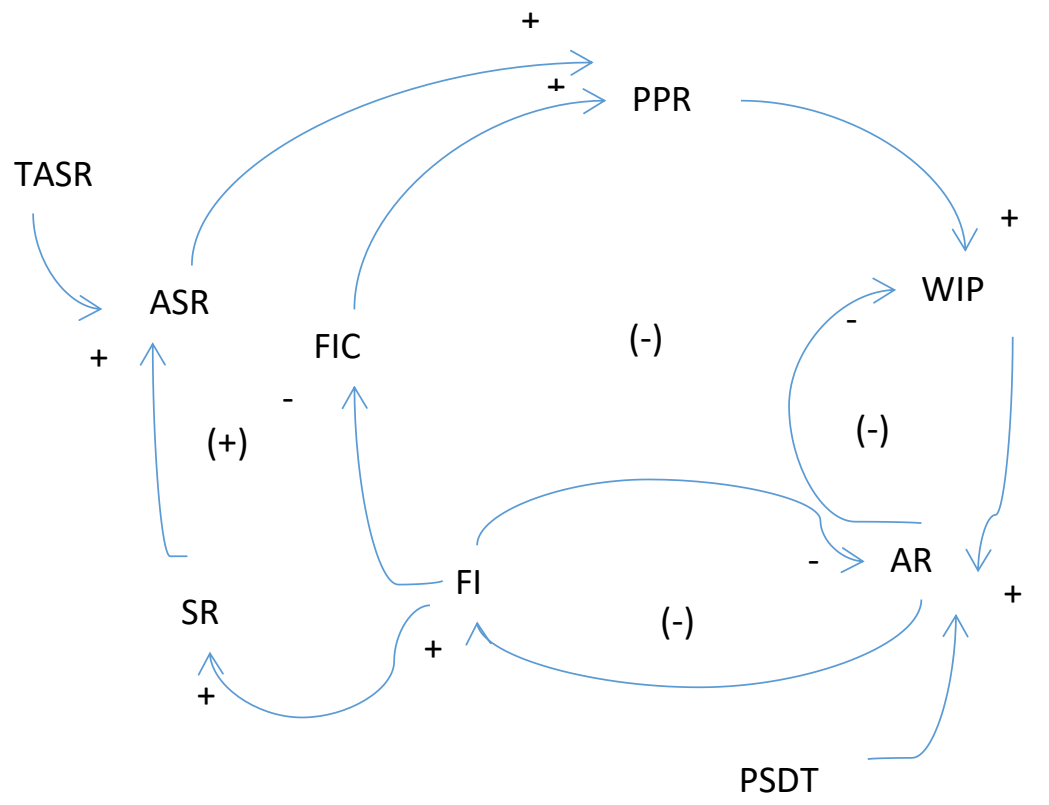

Figure 1

\subsection{Causal Loop Diagram:}

Causal loop diagrams are used to map the system structure and try to understand how the system behaves. The variables in the system are connected to the causal linkages. The direction of the arrow shows the direction of the cause-effect relationship. A positive sign means that when the variable at the tail of the arrow changes, the variable at the head always changes in the same direction. A negative sign has the opposite effect if the tail variable changes then the head variable changes in the opposite direction.

Figure 1 shows that the case company causal loop diagram, there are two distinct loops. The first loop controlling the Inventory control and second loop controlling production control. The balancing loop describes the company Finished Inventory (FI) status, Assembly Rate (AR) increases automatically FI increases, the availability of FI increases Finished Inventory Correction (FIC) decreases. If FIC increases Parts Production Rate (PPR) increases, the PPR increases obviously Work In Process (WIP) increases AR orders are also high. The reinforcing loop describes production requirements, if Shipment Rate (SR) increases Average Shipment Rate (ASR) also positive then PPR order rate also positive along with Time to Average Shipment Rate (TASR) and Parts Supply Delivery Time (PSDT) 


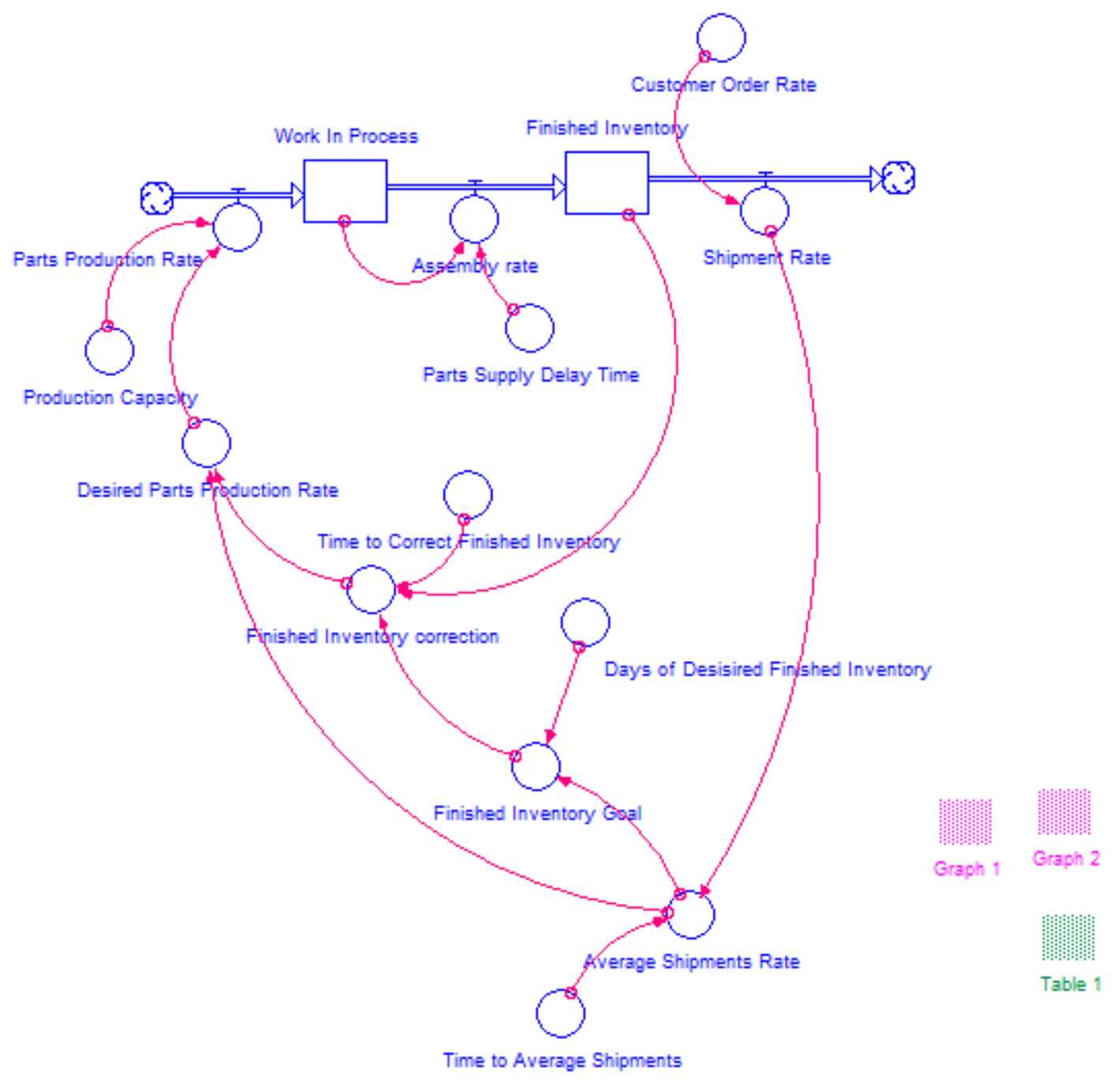

Figure 2: Stock Flow Diagram

\subsection{Stock Flow Diagram}

Figure 2 shows a complete stock-flow diagram for production and inventory control. It represents three regions operating policies and these regions more specific representations of material and information flows. The first region forecasting relies on information about the placements as well as an average of past shipments. It shows how quickly this response to average variations in the shipments. The average shipment is used in two different ways to monitor production planning. It feeds the component desired production through the production scheduling and also influences the inventory control. The factory is maintained some Inventory in the plant i.e desired Inventory to avoid stockout. The desired Inventory depends on the average shipment rate and desired days of finished Inventory coverage. The desired Inventory is compared with the present Inventory the manager has to decide whether to increase or decrease production to maintain the Inventory in the stock. The correction for finished Inventory captures the management decision, a concept called time to correct the Inventory that represents the necessity with which manager adjusts an Inventory shortage or surplus. The production scheduling gets the information from the average shipment rate along with the correction for Inventory to arrive at the desired production. 


\subsection{Model Analysis}

The retail order rate increases unexpectedly and permanently by 12 percent 500 to 560 units per day. Assuming that the plant can always able to produces at the assembly rate is equal to the desired finished Inventory. The first 20 days model is in perfect equilibrium the customer order rate had been steady for a long time. Fig. 3 shows that the shipment rate, customer order rate, average shipment rate, and assembly rate is equal to 500 units per day. Then on day 20 the customer order rate step increase by 12 percent thus the plant is able to supply the products for from safety stock to fully satisfy the demand at all times. The plant achieves this supply by depleting inventory and subsequently increasing the assembly rate not only to meet the customer demand but also to the Inventory. In the interval between day 20 and 94, the shipment rate and customer order rate exceeds the assembly rate. The outflow of the products exceeds inflow, due to this, the customer orders are filled from safety stock so the inventory starts declining. Now assembly rate is quickly reaching up to shipment by day 100 they are equal but Inventory control demands more products to assemble to replenish the Inventory.

\subsubsection{Forecasting of Shipments}

A forecast is an assumption, prediction or viewpoint of future event or condition usually as the basis for taking action. whenever people in the organization estimate, perceive or formally measure the conditions of the customer demand. The shipment rate is a reliable guide to future demand that can be expressed algebraically an average shipment rate. An average is determined based on a sum and thus an accumulation of shipments over a period of time. The value of the update depends on the difference between the shipment rate and average shipment rate, divided by the time to average shipment rate.

Average Shipments Rate $=$ SMTH3 (Shipment Rate, Time to Average Shipments)

Time to Average Shipments $=60$ days

\subsubsection{Inventory Control}

The desired Inventory is formulated as a product of the average shipment rate and days of desired inventory coverage. The coverage is set at 60 days consistent with organization policy to avoid the stockouts. The difference between desired Inventory goal and current inventory is an Inventory correction, this can be either cutting the production to eliminate surplus or increase the production to remedy a shortfall.

The managerial sense of urgency is captured in time to correct inventory.

Finished Inventory Goal $=$ Average Shipments Rate*Days of Desired Finished Inventory

Finished Inventory correction $=$

(Finished Inventory Goal- Finished Inventory)/Time to Correct Finished Inventory

\subsubsection{Desired Production}

The desired production is formulated as the sum of the average shipment rate and correction for Inventory. The desired production anchor the production plan to the average shipment, which is estimate or forecast of customer demand. Also, adjust the plan to take account of the surplus or shortage of inventory signalled by Inventory control.

Desired Parts Production Rate $=$ Average Shipments Rate + Finished Inventory correction 


\subsubsection{Assembly Rate}

The assembly rate depends on work in process and parts supply delay time. The model pull characteristic of assembly and finished goods, that must capture their dependency on current retail demand.

Assembly rate $=$ Work in Process/Parts Supply Delay Time

Parts Supply Delay Time $=60$

Table 1

\begin{tabular}{|l|l|l|l|l|}
\hline $\begin{array}{l}\text { Time to Correct } \\
\text { Finished } \\
\text { Inventory } \\
\text { (Days) }\end{array}$ & $\begin{array}{l}\text { Parts production } \\
\text { Rate } \\
\text { (Units) }\end{array}$ & $\begin{array}{l}\text { Assembly Rate } \\
\text { (Units) }\end{array}$ & $\begin{array}{l}\text { Finished } \\
\text { Inventory } \\
\text { (Units) }\end{array}$ & $\begin{array}{l}\text { Work in Process } \\
\text { (Units) }\end{array}$ \\
\hline 30 & 666 & 618 & 12545 & 37083 \\
\hline 60 & 630 & 603 & 12244 & 36246 \\
\hline 120 & 604 & 591 & 10790 & 35462 \\
\hline
\end{tabular}

\subsection{Scenarios in Policy Design}

A system dynamics model provides a vehicle for testing the effects of various policies on the behaviour of the overall system. Every policy has four components, desired conditions or goals, apparent conditions, speed of response and corrective action. Each component affects the performance of the enterprise. Desired conditions and apparent conditions are the information inputs to the policy and the time of response measures how quickly and aggressively management reacts to change conditions shown in Table 1.

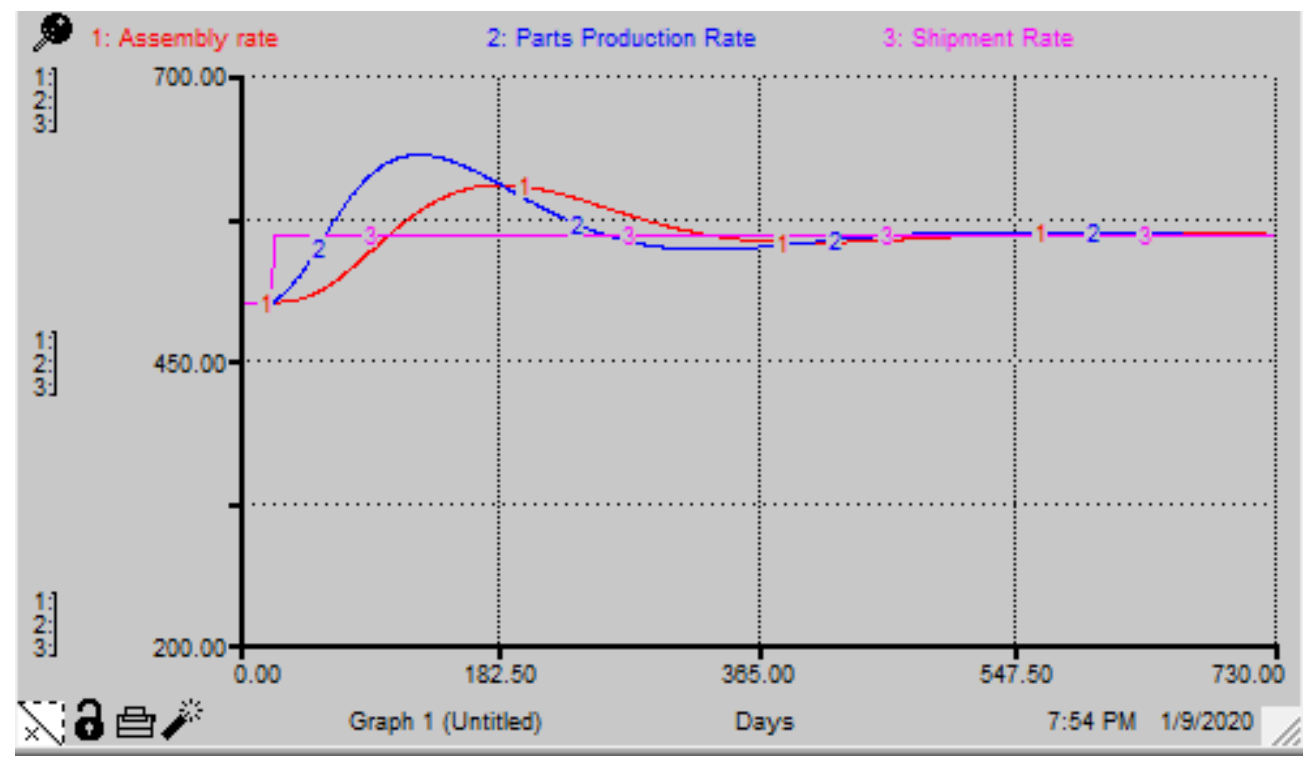

Figure 3 


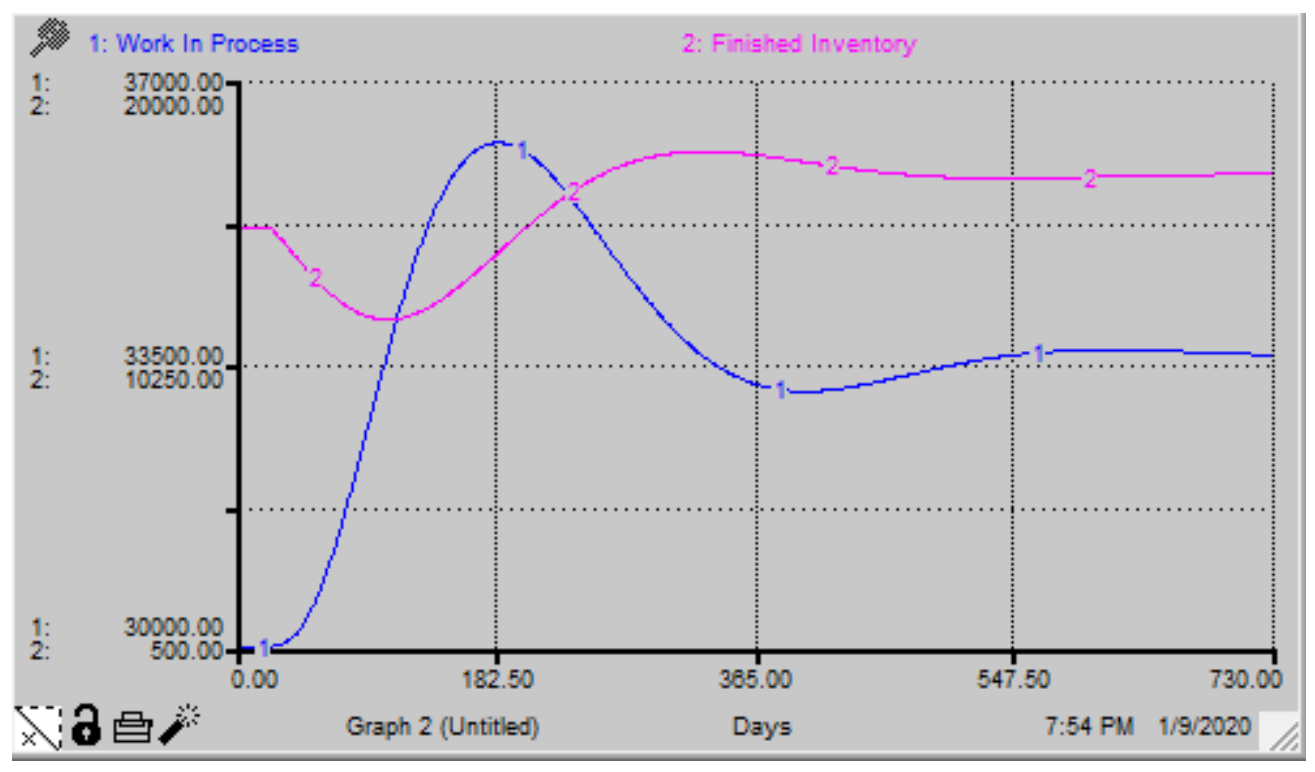

Figure 4

A step increase in customer order by 12 percent results in a 21 percent peak increase in assembly rate and a 26 percent peak in work in process, each stage disturbance and instability transmitted from the prior stage. The amount of amplification depends on time to correct the finished Inventory, the management responding to changes in assembly rate and in rebuilding the Inventory. Fig.xx gives the tree alternative policies. The moderate policy represents the current set of model parameters the assembly rate reaches to current customer order rate and the system stabilizes at 94 and 184 days respectively. The aggressive policy decreases the correction time from 60 days to 30 days. The slow policy increases the correction time from 60 days to 120 days shown in Fig. 3 and Fig. 4.

\section{Conclusions}

In this paper, the system dynamics model supported the enterprise in measuring their state of performance under increasing customer orders. The qualitative description of the enterprise through causal loop diagrams and qualitative analysis by stock-flow diagrams. system dynamics models help foresee the consequences of the various policy options. Here three policy options are discussed, under aggressive policy management responds quickly to adopts changes in the business and tries to correct the Inventory discrepancies. Where the inventory holding costs are high and should maintain Inventory all the time. The slow policy management is reluctant to correct the assembly rate immediately where the cost of changing is expensive and no danger about the stockouts. A moderate policy might be the characteristic of an organization in which the cost of holding Inventory is approximately the cost of instability.

Future research work will look at production control along with the workforce. The assembly rate depends on the size of the workforce and worker productivity; these two links are hardwired. 


\section{References}

[1] K. Efthymiou, A. Pagoropoulos, N. Papakostas, D. Mourtzis, G. Chryssolouris,.2012. Manufacturing Systems Complexity Review: Challenges and Outlook In CIRP Conference on Manufacturing Systems (pp. $644-649)$ CIRP

[2] A. Arafa, W.H. ElMaraghy,2011.Manufacturing strategy and enterprise dynamic capability In CIRP Conference on Manufacturing Systems (pp. 507-510) CIRP

[3] Paulo Goncalves, Jim Hines, John Sterman, The Impact of endogenous demand on push-pull systems, System Dynamics Review 21 no.3 (2005)187-216

[4] Purnendu Mondal, Amrik s .sohal, Modeling helps in understanding policy alternatives: A case Journal of management in engineering 14 no.1,(1998) 41-48.

[5] Tigist Fetene Adane, Maria Floriana Bianchi, Andreas Archenti, Mihai Nicolescu Application of system dynamics for analysis of performance of manufacturing systems Journal of Manufacturing Systems 53 (2019) 212-233

[6] HPS, 1996. ithink Software Package. Hanover, NH: High Performance Systems.

[7] Forrester JW. 1961. Industrial Dynamics. MIT Press: Cambridge, MA (now available from Pegasus Communications, Waltham, MA).

[8] Sterman JD 2000. Business Dynamics: Systems Thinking and Modeling for a Complex World., Irwin-McGraw-Hill: Chicago, IL. 